LA W RENCE LIVERMORE NATIONAL LABORATORY
Modeling Thermally Induced Failure of Brittle Geomaterials

S. D. C. Walsh

April 3, 2013 
This document was prepared as an account of work sponsored by an agency of the United States government. Neither the United States government nor Lawrence Livermore National Security, LLC, nor any of their employees makes any warranty, expressed or implied, or assumes any legal liability or responsibility for the accuracy, completeness, or usefulness of any information, apparatus, product, or process disclosed, or represents that its use would not infringe privately owned rights. Reference herein to any specific commercial product, process, or service by trade name, trademark, manufacturer, or otherwise does not necessarily constitute or imply its endorsement, recommendation, or favoring by the United States government or Lawrence Livermore National Security, LLC. The views and opinions of authors expressed herein do not necessarily state or reflect those of the United States government or Lawrence Livermore National Security, LLC, and shall not be used for advertising or product endorsement purposes.

This work performed under the auspices of the U.S. Department of Energy by Lawrence Livermore National Laboratory under Contract DE-AC52-07NA27344. 


\title{
Modeling Thermally Induced Failure of Brittle Geomaterials
}

\author{
Final Technical Report
}

\author{
Stuart D.C. Walsh
}

\begin{abstract}
Geothermal power promises clean, renewable, reliable and potentially widely-available energy, but is limited by high initial capital costs. Widespread adoption of geothermal energy will require access to deeply buried geothermal sources in granitic basement rocks at high temperatures and pressures. Exploiting these resources necessitates novel methods for drilling, stimulation, and maintenance, under operating conditions that are difficult or impossible to test in laboratory settings. In such environments, physically rigorous numerical modeling tools are vital to highlight potential risks, guide process optimization and reduce the uncertainties involved in these developing technologies.

A drilling technology with the potential to reduced the costs associated with geothermal power is Thermal Spallation Drilling (TSD) a novel drilling technique in which small particles (spalls) are released from the rock surface by rapid heating. While TSD has the potential to improve drilling rates of brittle granitic rocks that are typical for geothermal wells, the coupled thermomechanical processes involved in TSD are poorly described, making system control and optimization difficult for this drilling technology.

The project examined the factors influencing thermal spallation of hard basement rocks. Under the project, high-resolution simulations employing Lawrence Livermore's GEODYN code were used to model spallability of different rock types as a function of grain size distribution and depth, at conditions appropriate for geothermal wells. Data collected from these simulations was used to provide qualitative information on the rocks and conditions best suited to Thermal Spallation Drilling and related rock reduction technologies. The results of the simulations were analyzed to extract parameters for future validation of empirical models describing thermal spallation at the borehole scale. This work performed under the auspices of the U.S. Department of Energy by Lawrence Livermore National Laboratory under Contract DE-AC52-07NA27344. IM Release Number: LLNL-TR-632239
\end{abstract}




\section{Introduction}

Wells for Engineered Geothermal Systems (EGS) occur in conditions that present significant challenges for conventional rotary and percussive drilling technologies: granitic rocks that reduce drilling speeds and cause substantial equipment wear. Thermal spallation drilling, in which rock is fragmented by high temperature rather than mechanical means, offers a potential solution to these problems. However, much of the knowledge surrounding this drilling technique is empirical - based on laboratory experiments that may or may not represent field conditions. There is a lack of understanding coupled with large uncertainties in the phenomenology of the process which could be resolved with computer modeling.

System-scale simulations of thermal spallation employ phenomenological models of rock damage due to the thermal gradient and erosion of spalls by the fluid. This allows rapid evaluation of mass and energy balances near the drill head and parametric studies of the relationship between drilling performance and the parameters of the jet. However, large-scale modeling is not suitable for resolving rock grains and inhomogeneities, and the damage model must account for the temperature gradient not typically used as an input parameter in such material models. Thus, the parameters governing such phenomenological damage models require calibration by mesoscale simulations that fully resolve rock grains.

The project examined the factors influencing thermal spallation of hard basement rocks. Under the project, high-resolution simulations employing Lawrence Livermore's GEODYN code were used to model spallability of different rock types as a function of grain size distribution and depth, at conditions appropriate for geothermal wells. Data collected from these simulations was used to provide qualitative information on the rocks and conditions best suited to Thermal Spallation Drilling and related rock reduction technologies. The results of the simulations were analyzed to extract parameters for future validation of empirical models describing thermal spallation at the borehole scale.

Rapid heating of certain rock-types causes thin disk-like fragments or "spalls" to be removed from the surface in a process known as thermal spallation. Thermal spallation in rock is widely regarded to follow a mechanism first described in the 1920's and 1930's [1,2]. Due to the rock's low thermal conductivity, heating produces large temperature gradients and associated compressive stresses close to the surface. The compressive stresses cause fractures to emanate from pre-existing flaws. The fractures extend outward parallel to the rock surface, following the principle compressive stresses. If 
an induced fracture propagates to a sufficient extent, the heated fragment buckles and is ejected as a spall (Figure 1). Thermal spallation has long been of interest as a means of achieving faster penetration compared to conventional mechanical drilling methods, particularly for brittle granitic rocks [3-5]. Applications include blast hole drilling, quarrying, deep-well drilling, cavity formation and well stimulation [5-9]. Fire-induced spallation of rock has also been identified as a growing concern in tunnel and mine safety [10-13].

At present, models of spall production remain largely empirical in nature or adopt simplifying assumptions that ignore microstructural heterogeneity. For example, several analytical models have been developed based on buckling theory (e.g. $[14,15])$. The advantage of these models is that they present a closed-form solution that can be rapidly evaluated. However, for the most part such models assume a homogeneous material body, making it difficult to predict changes in the spallability of different rock types. To overcome these limitations, researchers examining thermal spallation in granitic rocks have employed Weibull statistical failure theory [16] to represent the relationship between microstructural heterogeneity and the rock's propensity to spall [17-20]. Such Weibull models have been successfully used to predict such factors as penetration rate, spall-size distribution and borehole radius from drilling jet velocity and applied heat flux $[19,20]$.

Nevertheless, although useful for predicting system response in a given context, Weibull models are empirically derived. As such, the model parameters must be carefully fitted from laboratory tests. Moreover, such models may overlook material behavior outside of model assumptions. For example, while Weibull models of spallation postulate the existence of a distribution of critical flaws, they make no claims to the nature of these flaws or how the distribution should change according to rock composition. Consequently, it can be difficult to determine how these models should behave outside the experimental scope from which they are fitted. Indeed for many applications (thermal spallation drilling in particular) it may be prohibitively expensive to conduct appropriate experimental investigation under the appropriate conditions or impossible to obtain the relevant experimental data. In such an environment, explicit small-scale numerical simulations can be used to provide insight into the fundamental processes contributing to thermal spallation.

In the following report, we detail the results of a series of high-resolution simulations investigating thermal spallation processes at the grain scale. A brief outline is provided of the numerical simulators used in the project, GEODYN and PSUADE, along with a detailed description of the microstruc- 
tural models used to represent thermal spallation at the grain scale. The explicit grain-scale model is used to investigate the grain spallation for a variety of different drilling conditions: examining varying temperature, pressure, material properties and microstructural configurations. The results of the model illustrate the susceptibility of specific sites within the rock body to failure, lending credence to the use of Weibull failure models of spall production which assume a distribution of critical flaws within the rock body at which spalls are initiated. New results from the simulations, however, also suggest ways in which Weibull models may be improved: in particular, by accounting for the effect of micropores and variable spall aspect ratio. While the effect of vapor pressure on thermal spallation, is a principle concern in the cement literature, it has been largely overlooked in rock spallation due to the low porosity of granites. Nevertheless our simulations suggest that micropores may be significant in even low porosity rocks as they serve as sites for fracture initiation. Likewise, we present results from both our simulations and analysis we have conducted on spall particles obtained from field tests by Potter Drilling, examining the relationship between spall aspect ratio and particle size. The simulated spalls and the collected field-test particles both demonstrate more equant shapes at smaller sizes. We show how this size dependent aspect ratio can be incorporated into a Weibull model of spall production, and discuss its effect on the relationship between the rate of penetration, applied heat flux and surface temperature. We conclude the report by providing recommendations on future avenues of research, and the ways in which insights from this study may be included in future modeling efforts.

\section{Numerical simulators: GEODYN and PSUADE}

The simulations presented in this report are conducted using the geomechanical simulator, GEODYN, developed at Lawrence Livermore National Laboratory. GEODYN is a parallel Eulerian compressible-solid and fluiddynamics code with adaptive mesh refinement (AMR) capabilities [21,22]. Its features include a high-order material interface reconstruction algorithm [23] and advanced constitutive models that incorporate salient features of the dynamic response of geologic media [24]. GEODYN is able to simulate materials under extremely large deformations, resolve details of wave propagation within grains with high accuracy. Moreover, as it employs a continuum damage mechanics approach to represent fracturing, it is able to simulate fracture propagation within grains. This modeling capability is necessary, 


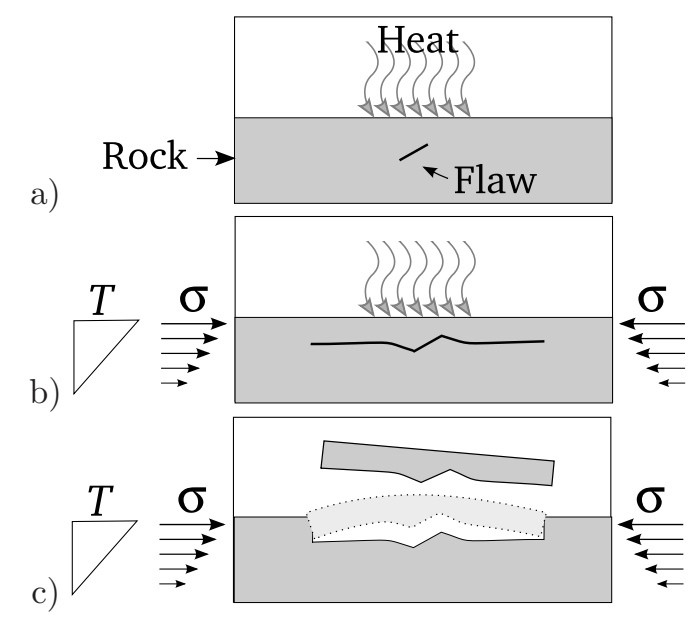

Figure 1: Spall-production model proposed by Preston [1,2]: a) An applied heat flux increases the temperature of the rock face, increasing the compressive stresses adjacent to the surface. b) The compressive stresses cause fractures to grow parallel to the surface from incipient flaws in the rock. c) Upon reaching a critical size, the heated region buckles and is ejected from the surface as a spall. 
as spalls are disk-like in shape; often one or-more grain-diameters in extent with thicknesses below a single grain diameter [7,25].

Sampling design for the parameter space studies in this report was conducted with a second Livermore code, PSUADE [26]. PSUADE is a software toolkit to facilitate uncertainty quantification. It contains functionality to conduct uncertainty analysis, global sensitivity analysis, design optimization and model calibration, and supports a global sensitivity methodology for models with large numbers of parameters and complex constraints. It includes methods for sampling, automated simulation execution, and analysis. The computational resources required by PSUADE are negligible in comparison with the thermal spallation simulations conducted with GEODYN.

Both GEODYN and PSUADE include flexible command-line interfaces for coupling with other codes. Indeed, PSUADE's interface is particularly simple - the input and output files for each sample point consist of a text file with a single column of parameters. Nevertheless, additional coupling scripts are required to interface these two programs - in particular, routines are required to interpret PSUADE's input parameters and generate initial conditions for GEODYN (most notably grain geometries), and extract the appropriate scalar parameters from the simulation output. In principle these tasks could be accomplished with separate coupling scripts for each set of PSUADE simulations. However, the task of monitoring and maintaining these separate scripts can rapidly grow in complexity, particularly in the face of unexpected events: tracking failed runs due to unphysical parameters, system downtime or resource restrictions, or while debugging the preprocessing-simulation-postprocessing workflow. As a result, along with the high degree of overlap in the tasks required of these coupling scripts, a separate GEODYN-PSUADE interface was employed to control the PSUADE simulation runs. The GEODYN-PSUADE interface provided a simple-to-use, but inherently flexible Python wrapper to both codes, which also acts as a repository for common subroutines required in multiple simulation runs, enhancing maintainability. In addition the interface is easily extended to include additional input and output parameters and allows for customizable runs, permitting the GEODYN simulations to either be conducted in at PSUADE's behest or completely independently. The former mode is necessary for optimization studies (a long-term goal of the LLNL-Potter Drilling collaboration), while the latter mode facilitates embarrassingly parallel parameter-space exploration (the primary goal of the present investigation). As such the interface allows any sensible combination (attempting to conduct preprocessing and postprocessing steps without 


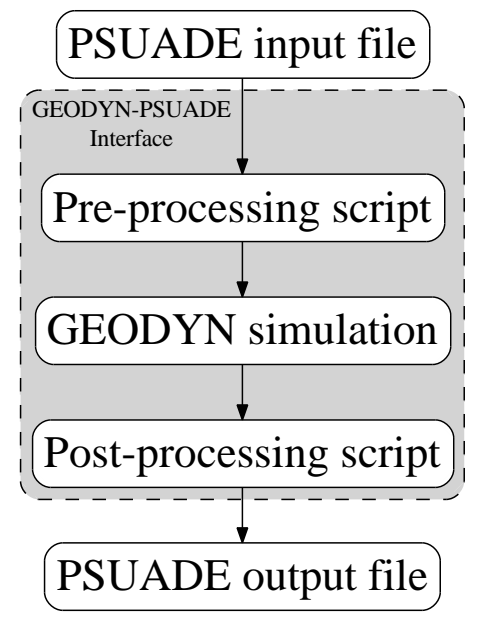

Figure 2: GEODYN-PSUADE interface

the intermediate simulation step is not permitted) of preprocessing, simulation and postprocessing steps may be carried out independently or in series, on all or part of the simulation runs. This aids in preserving computing resources (for example, by allowing the typically single-processor pre- and post-processing to be conducted independently, while the computationally intensive GEODYN simulation is performed in parallel) and simplifies debugging.

\section{Model description}

The Eulerian-Godunov method implemented in GEODYN is a modified version of a single-phase high-order Godunov method that has been extended to track multiple material bodies. For solid materials, the governing equations consist of the laws of conservation of mass, momentum and energy, an equation for elastic deformation, and additional equations in the form:

$$
\frac{\partial}{\partial t}\left(\rho F_{i}\right)+\nabla \cdot\left(\rho \mathbf{v} F_{i}\right)=\rho \Phi_{i},
$$

which represent specific rheological equations $\dot{F}_{i}=\Phi_{i}$ (superposed dot denotes material time differentiation) for history dependent state and internal variables $F_{i}$ (damage, plastic strain, etc.). Propagation of surfaces in space is similarly modeled via an equivalent evolution of volume fractions, defined 
by:

$$
\frac{\partial \phi_{\alpha}}{\partial t}+\nabla \cdot\left(\phi_{\alpha} \mathbf{v}\right)=\frac{\phi_{\alpha}}{K_{\alpha}} K \nabla \cdot \mathbf{v},
$$

where $\phi_{\alpha}$ and $K_{\alpha}$ are the volume fraction and the bulk modulus of each material $\alpha$.

The numerical scheme for a single cell is based on the approach of [27], with modifications to account for the full stress tensor associated with solids. The multidimensional equations are solved by using an operator splitting technique, in which the one-dimensional equations for each direction are solved:

$$
\begin{aligned}
& U_{i, \alpha}^{n+1}=S_{H}\left(S_{1,0,0}\left(S_{0,1,0}\left(S_{0,0,1}\left(U_{i, \alpha}^{n}\right)\right)\right)\right), \\
& U_{i, \alpha}^{n+2}=S_{H}\left(S_{0,0,1}\left(S_{0,1,0}\left(S_{1,0,0}\left(U_{i, \alpha}^{n+1}\right)\right)\right)\right),
\end{aligned}
$$

where the spatially split operators

$$
S_{i_{\beta}, j_{\beta}, k_{\beta}}\left(U_{1, \ldots, l, \alpha}^{n+m / 3}\right)
$$

are applied in a Strang-splitting order to keep second-order accuracy, while the source term

$$
S_{H}\left(U_{1, \ldots, l, \alpha}^{n, H}\right)=U_{1, \ldots, l, \alpha}^{n, H}+\Delta t V_{\alpha} H_{\alpha}\left(U_{1, \ldots, l, \alpha}^{n, H}\right)
$$

is always applied at the end of the timestep. Each directional operator is the update of the cell from time step $n$ to time step $n+1$ with fluxes computed at cell edges. Edge fluxes are calculated based on upwind characteristic tracing following [27], using an acoustic approximate Riemann solver. The velocity gradient estimate in equation (6) is calculated in the Riemann-solver step.

Multiple-material cells are treated in a similar manner to that in [27]: material properties have multiple values in a cell, but the velocity and stress are single-valued. It is therefore necessary to define an effective mixed-cell phase and to update material volume fractions based on self-consistent cell thermodynamics:

$$
\begin{aligned}
& 1 / K=\sum \phi_{\alpha} / K_{\alpha} \quad T_{i i}=K \sum \phi_{\alpha} T_{i i \alpha} / K_{\alpha} \\
& 1 / G=\sum \phi_{\alpha} / G_{\alpha} \quad T_{i j, i \neq j}=G \sum \phi_{\alpha} T_{i j \alpha} / G_{\alpha}
\end{aligned}
$$

where $G_{\alpha}, T_{i j \alpha}$ are the shear modulus and the stress tensor of material $\alpha$. The velocity gradient assigned to each material in the cell is similarly:

$$
\mathbf{L}_{\alpha}=\mathbf{L} G / G_{\alpha} .
$$


Heat transport is governed by

$$
\mathbf{q}=-\lambda \nabla \Theta
$$

where $\mathbf{q}$ is the heat flux, $\lambda$ is the thermal conductivity and $\Theta$ is the temperature. Thermal conductivity is calculated from the following mixture rule:

$$
\lambda=\left(\sum_{\alpha} \phi_{\alpha} \lambda_{\alpha}+\frac{1}{\sum_{\alpha} \phi_{\alpha} / \lambda_{\alpha}}\right)
$$

i.e. the thermal conductivity is taken to be the average of the weighted arithmetic and harmonic means of the thermal conductivities for the individual material components, $\lambda_{\alpha}[28]$. A high order interface reconstruction method is used to advect volume fractions in such a way that linear interfaces are preserved during translation. The volume fractions are constrained by assuming fast equilibration of partial pressures in the cell. The pressure relaxation algorithm consists of iterative adjustments of volume fractions. The average pressure is first calculated:

$$
p=\sum_{\alpha} \frac{f^{\alpha} p^{\alpha}}{K^{\alpha}} / \sum_{\alpha} \frac{f^{\alpha}}{K^{\alpha}},
$$

from which, the change of volume fraction for current iteration step is determined:

$$
\delta \phi_{\alpha}=\beta_{\alpha} \phi_{\alpha}\left(p^{\alpha}-p\right) / K^{\alpha} .
$$

The limiter $\beta_{a}$ in (12) is chosen from numerical and physical considerations, i.e. volume fractions are restricted between zero and one, change of material density should be limited, etc.

The rock microstructures employed in the simulations are created by fitting the cells in a Voronoi tessellation to a target grain-size distributions [29]. Voronoi cells are generated from a set of random points, and each cell is assigned a target volume. In this manner, separate grain-size distributions may be set according to mineral type, or even on a grain-by-grain basis. The Voronoi-cell volumes are then relaxed towards the target distribution over a series of iterations, in which the cell centers are updated according to:

$$
\mathbf{X}^{\text {new }}=\mathbf{X}^{\text {old }}+\left[\frac{\partial \mathbf{V}}{\partial \mathbf{X}}\right]^{\dagger}\left(\mathbf{V}_{\text {target }}-\mathbf{V}\right)
$$

where $\mathbf{X}$ is a vector of coordinates for the cell-centers; $\mathbf{V}$ and $\mathbf{V}_{\text {target }}$ are vectors of Voronoi-cell volumes and target volumes respectively; and $\mathrm{A}^{\dagger}$ 


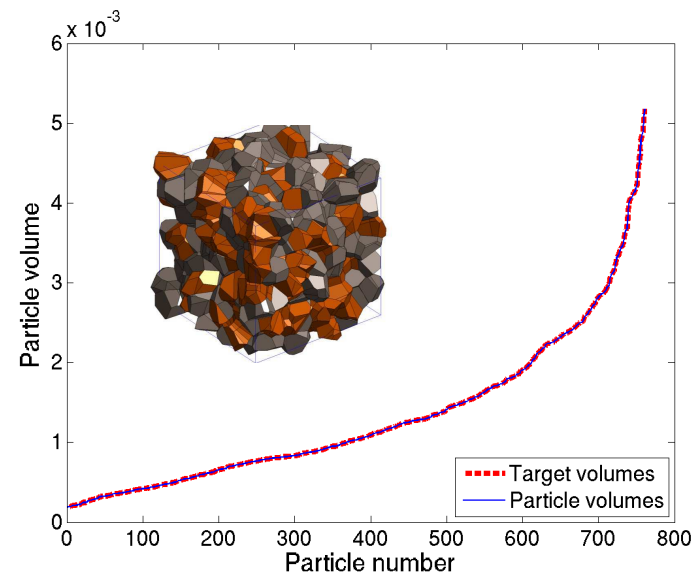

Figure 3: Grain microstructures used in the simulations are generated using a Voronoi cell based method in which voronoi cells perturbed over a series of iterations to fit a pre-determined particle size distribution. Target (dashed line) and generated (solid line) particle-size volume for a three dimensional assembly (inset figure).

indicates the pseudo-inverse of the matrix A. Construction of the $\frac{\partial \mathbf{V}}{\partial \mathbf{X}}$ matrix is described in the appendices. The iterative improvement is repeated until the average error in cell volumes is below a predetermined tolerance (typically less than $1 \%$ error in cell volumes). The method is capable of reproducing two and three dimensional grain-size distributions to arbitrary accuracy, and is able to produce microstructures with periodic and radially symmetric boundary conditions (Figure 3). Non-ergodic microstructures, where the particle-size distribution varies from location to location, are also possible - enabling, for example, consideration of layered media.

The multi-material method in GEODYN allows minerals with distinct material properties to be assigned to each grain in the assembly, as well as separate fluid components with distinct constitutive models. Here grain microstructures consisting of quartz, plagioclase feldspar and potassium feldspar (K-spar) are presented, but additional mineral types can also be introduced. The physical properties assigned to the minerals are summarized in Table 1. Mechanical parameters are taken from Bass [30] and Mavko et al. [31], while the heat capacities and relative thermal conductivities are based on values reported in Findikakis [32], Holland \& Powell [33] and Clauser \& Huenges [34]. Inter-grain contacts are represented by a separate, weaker material with compressive and tensile strengths fitted 


\begin{tabular}{lccccc}
\hline Mineral & Density & Bulk modulus & Poisson ratio & Heat Capacity & Thermal conductivity \\
\hline K-spar & $2.63 \mathrm{~g} / \mathrm{cm}^{3}$ & $53.7 \mathrm{GPa}$ & 0.28 & $0.93 \mathrm{~J} / \mathrm{g} . \mathrm{K}$ & $1.5 \mathrm{~W} / \mathrm{m} . \mathrm{K}$ \\
Plagioclase & $2.56 \mathrm{~g} / \mathrm{cm}^{3}$ & $50.8 \mathrm{GPa}$ & 0.26 & $0.93 \mathrm{~J} / \mathrm{g} . \mathrm{K}$ & $1.5 \mathrm{~W} / \mathrm{m} . \mathrm{K}$ \\
Quartz & $2.65 \mathrm{~g} / \mathrm{cm}^{3}$ & $37.0 \mathrm{GPa}$ & 0.08 & $0.93 \mathrm{~J} / \mathrm{g} . \mathrm{K}$ & $7.7 \mathrm{~W} / \mathrm{m} . \mathrm{K}$ \\
\hline
\end{tabular}

Table 1: Material properties used in the simulations arranged by mineral type.

to granite properties described by Lockner [35]. The rate at which heat is transmitted into the rock $(\mathrm{O}(\mathrm{m} / \mathrm{h}))$ is orders of magnitude slower than the speed of fracture propagation $(\mathrm{O}(\mathrm{km} / \mathrm{s}))$. Accordingly, the simulated thermal conductivities are artificially increased by a factor of 10,000. This has the effect of reducing simulation times, while maintaining a quasi-static temperature profile over fracture timescales. When included in the simulations conducted in this publication, microporosity is explicitly represented as fluid-filled inclusions of predetermined diameter and volume fraction.

\section{Results and discussion}

Results from the model demonstrate the importance of heterogeneous material properties and geometry in determining brittle failure - factors that would be impossible to investigate with homogenous continuum-scale models. In particular, the idealized, semi-infinite body assumed under the Preston model $[1,2]$ does not exist in reality: for example, the surface is not flat but roughened (particularly after spallation); the solid body may develop additional fractures as a consequence of the spallation; and the stress-state is non-uniformly distributed. Surface roughness, grain size distribution, and thermal conductivities therefore serve to generate local stress concentrations that trigger the onset of spallation [36,37]. Likewise, inter-granular boundaries are frequently sites of spall fracture initiation [7] (Figure 4). These boundaries cause discontinuities in the temperature profile that concentrate thermally induced stresses at the interface. Importantly, inter-grain boundaries are also sites of existing grain damage, containing a higher density of micro-fractures than within the grains [38].

Plots of spall size distributions obtained from the model are found to follow a log-normal distribution (Figure 6). Figure 7 shows the logarithmic means of spall size distributions obtained from a from a suite of 125 simulations, which varied the lithostatic and hydrostatic pressure, rock microstructure, and the fluid and host rock temperature differential. Plotting these results as a function of both the difference in rock and fluid tempera- 
a)

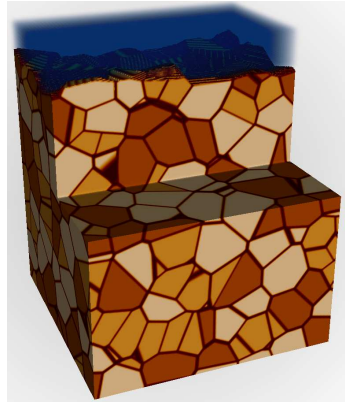

c)

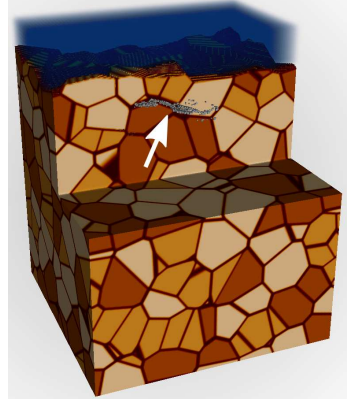

b)

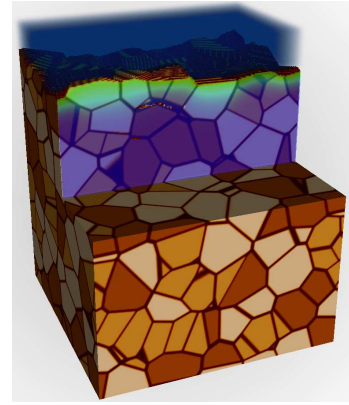

d)

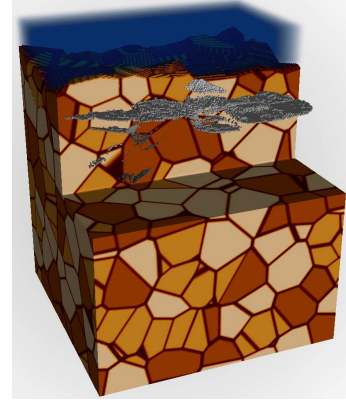

Figure 4: Fracture initiation and propagation in a three-dimensional grainscale simulation. a) Cutaway of the grain microstructure: light colored grains are quartz; orange grains are k-spar; brown grains are plagioclase. b) The rock face is heated by fluid in the transparent region at the top of the image, causing a thermal front to propagate into the rock. c) Fractures (gray planes in cutaway section indicated by white arrow) tend to initiate at inter-grain boundaries, d) but propagate along the thermal front, following the principal compressive stresses. 
ture, and the ratio of hydrostatic to lithostatic pressure, reveals two distinct groups of simulations. In one group, namely those conducted with fluid temperatures less than $\sim 300^{\circ} \mathrm{C}$ above the ambient rock temperature, there is little or no spalling in any of the simulations. Above $300^{\circ} \mathrm{C}$, however, the simulations exhibit a greater tendency to spall with increasing temperature (those that do not tend to have a higher ratio of hydrostatic to lithostatic pressure). Moreover, as the amount of energy in the system is increased (whether it be in the form of thermal energy, or potential energy due to the difference in pressures) the amount of damage also grows - resulting in smaller spall-sizes.

This damage is not arbitrarily distributed, however. Specific sites within the rock structure are found to be more susceptible to failure than other locations. This is illustrated in Figure 5, where the distributions of damage are shown for several simulations with the same microstructure, but different applied fluid temperatures. While the number of failure sites increases with temperature (decreasing the spall-sizes), a site prone to fracture at a lower temperature will also tend to fracture at higher temperatures. This lends credence to the use of Weibull models to represent spall production with assume the existence of a distribution of critical flaws that fail upon exceeding a given stress state $[7,19]$.

However, while the Weibull model predicts the existence of such a critical flaw distribution, it says nothing about the nature of these flaws. Nevertheless, theories regarding the makeup and activation of such critical flaws can be investigated using explicit grain-scale models of the type outlined in this paper. In our simulations fracture initiation tends to be more prevalent at quartz grain boundaries. The quartz content (more than the other minerals) is a more important factor in determining propensity to spall, due to its higher thermal conductivity and distinctive mechanical properties. This observation is also supported by previous experimental work by Soles and Geller [25] which found an increased propensity to spall with the volume fraction of quartz, and thermoelastic grain-scale simulations by Rauenzahn and Tester $[7,39]$ which demonstrated that the difference in thermal expansion between quartz and feldspar crystals was sufficient to cause fracturing. However, mineral heterogeneity is not the only possible means of generating stress concentrations in the rock microstructure. In particular, our models show that damage initiation is strongly affected by microporosity. 

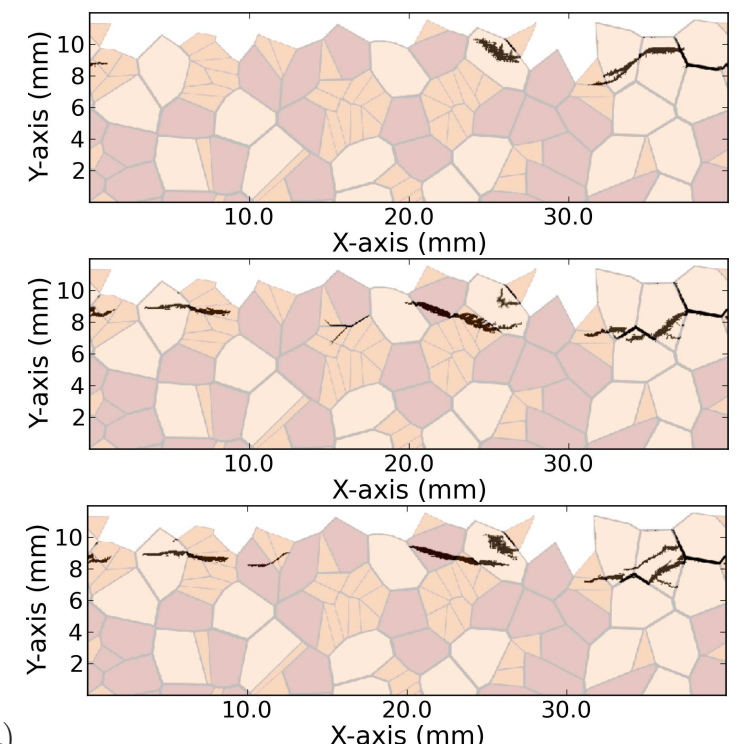

a)

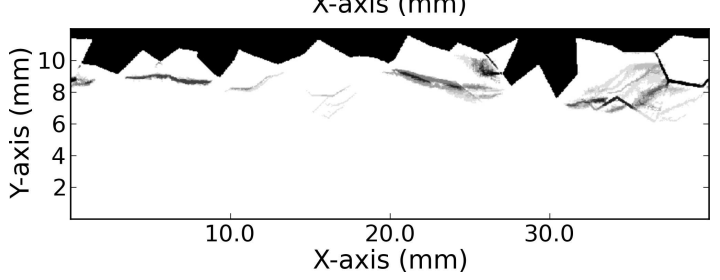

Figure 5: Illustration of the damage distribution as a function of the applied surface temperature (a). An amalgam of damage locations from eight simulations with fluid/rock temperature differentials between $370^{\circ} \mathrm{C}$ and $510^{\circ} \mathrm{C}$ is given in b) highlighting the locations most likely to fail. 


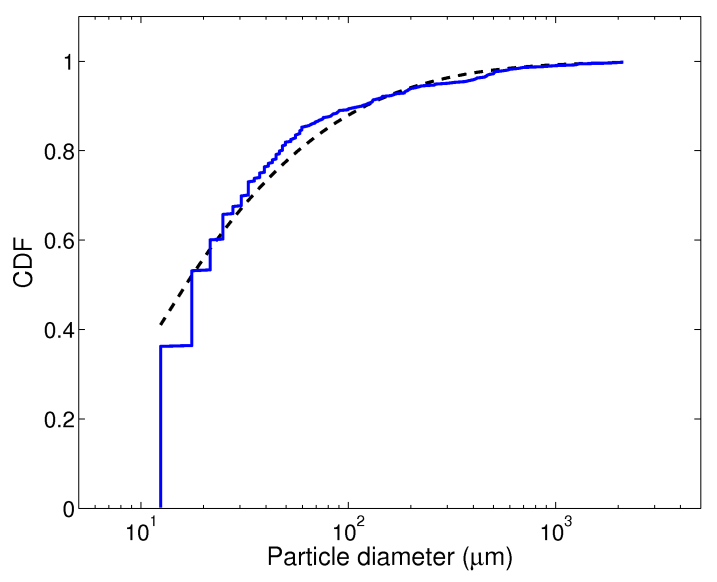

Figure 6: Spall sizes predicted by the model (solid line) are found to follow a lognormal distribution (dashed line).

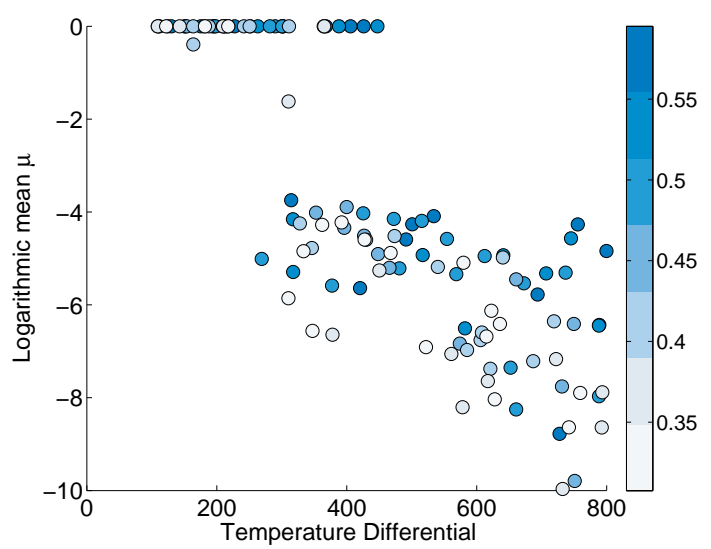

Figure 7: Fitted logarithmic mean of spall size distributions from 125 simulations varying lithostatic and hydrostatic pressure, rock microstructure, and the fluid and host rock temperature differential. The color indicates the ratio of fluid pressure in the borehole to the in-situ lithostatic pressure. Zero logarithmic mean indicates no spallation. 


\section{Microporosity}

Expansion of in-situ fluids has been recognized as a central, if not the most important, factor in driving spall production in bricks and concrete [40-43]. However, it has largely been assumed that water content plays less of a role in the spall of rock - where buckling failure is thought to dominate (a notable exception is the work by Hettema et al. [44], who examined the role of steam pressure in sedimentary rocks). This is presumably due to the low porosity of granitic rocks; however, by overlooking the effects of fluid content several key factors are ignored. First, the traditional buckling model of spall-production is essentially a bifurcation event [14]. Hence, small fluctuations in the stress-state can have a large impact on the onset and extent of spall production. This is reflected in Hettema et al. [44] who found that "steam pressures do not initiate but do contribute to the process of thermal spalling", and that oven-dried samples failed to spall under thermal shock loading. It is also seen in some cement studies which report that heating induced pore-pressure contributes to "buckling-risk" [42]. Cement studies also demonstrate that permeability is influential in vapor driven spallation: lower permeability cements have higher risk of spallation as they are less able to release the build-up in vapor pressure [45]. Though small in volume, fluid filled pores in rocks would experience increased higher pore pressure for extended durations due to the decreased permeability. Finally, rock porosity is unevenly distributed. For example, plagioclase grains may have as much as $2.5 \%$ pore-space by volume [46], and pore space can be concentrated at zones of weakness, for example at grain interfaces $[46,47]$.

In Figure 8, the effect of microporosity is investigated by comparing two simulations with identical grain microstructure except for the addition of water-filled micropores at $0.1 \%$ porosity in one of the simulations. The microporosity is introduced into the simulation as randomly distributed circular pores of equal diameter. Despite the low volume fraction, the porosity serves to both increase the extent of damage and decrease the spall-size distribution. The latter point is made more evident in Figure 9, which plots spall-size distributions and the distribution of logarithmic means from a suite of simulations, in which the grain microstructure remained constant but microporosity was varied. Importantly, the addition of the microporosity also alters the locations of fracture initiation. New fractures are almost exclusively generated at the micropores.

The results of these simulations do not support a vapor-pressure driven model of spallation, as has been argued in the cement literature [43, 48]. The vapor pressure induced in low-porosity granitic rocks is insufficient to 


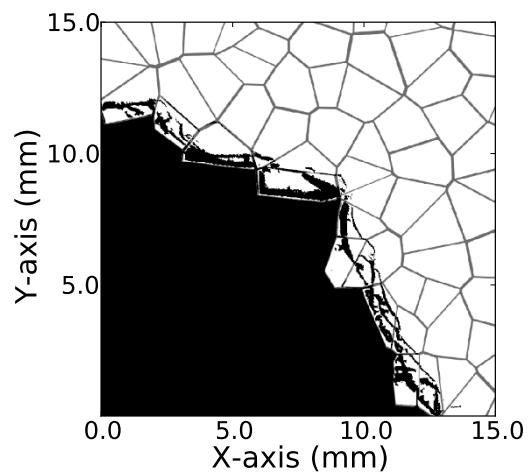

a)

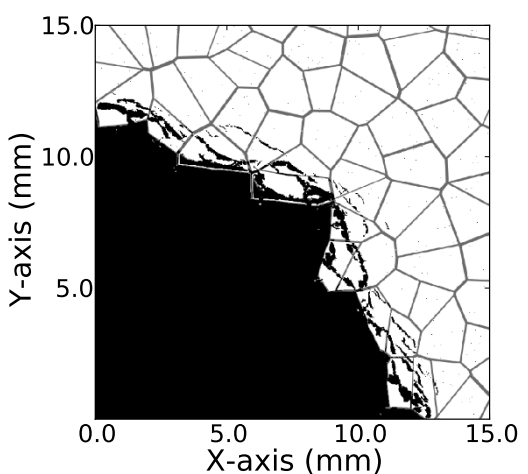

b)

Figure 8: Comparison of damage distribution in simulations a) without microporosity and b) with $20 \mu \mathrm{m}$ radii micropores at $0.1 \%$ porosity. 
cause spallation in and of itself. However, the simulations results show that the microporosity does influence the pattern and type of spallation observed. This suggests a modified version of the traditional buckling model (Figure 10), in which spall fracture is both initiated at micropores and then aided by the expansion of the fluids inside those pores.

\section{Aspect Ratio and Spall Size}

An assumption commonly employed in continuum models of spall damage is that idealised disk shaped spalls are produced with a constant ratio of spall thickness to particle radius. Results from the numerical simulations, along with observations of spalls collected from field and laboratory tests however, suggest that spall aspect ratio is in fact dependent on the spall size distribution. Changes to the spall aspect ratio influenced by microstructural heterogeneity, particularly as the size of the spall particle approaches, or falls below, that of individual mineral grains. This is important as in many cases, the modal spall diameter can fall to $1 \mathrm{~mm}^{3}$ or less, as indicated in Figure 11 which shows spall particle size distributions from laboratory tests by Potter Drilling.

To investigate the distribution of spall aspect ratios further, a study was conducted examining changes to spall thickness as a function of the crosssectional area. Spall-samples collected from a thermal spallation drilling field-test were sorted by size into six categories: extremely large spalls (over $0.5 \mathrm{~cm}$ in size); spalls greater than $2000 \mu \mathrm{m}$ in size; spalls between $1400-$ $2000 \mu \mathrm{m}$; spalls between $850-1400 \mu \mathrm{m}$; spalls between $300-850 \mu \mathrm{m}$; and spalls below $300 \mu \mathrm{m}$ in size. Digital images of the spalls were then obtained under a microscope with both angled and diffuse light sources, and image analysis conducted to extract the extent of the shadows (Figure 12). The feature heights were determined from the shadow extents by calibrating against the shadow of a silicon plate of known thickness, while shadow extents were used to determine the in-plane width of each spall particle (Figure 12b).

The spall sizes and thicknesses obtained from the angled-light images are plotted in Figure 12d, and the aspect ratio (size/thickness) for the spalls given in Figure 12d. The larger spalls examined in the analysis exhibit an aspect ratios between and 4:1 and 10:1 diameter to thickness. This is slightly smaller than previous reported aspect ratios from experiments (between 8:1 and 15:1 [49]) and estimates based on plate and beam buckling theories (which estimate ratios between 10:1 and 15:1 [17]). In part the smaller aspect ratios is partially a product of the manner in which the measurements were collected. As here the focus has been on bulk measurement of a large 


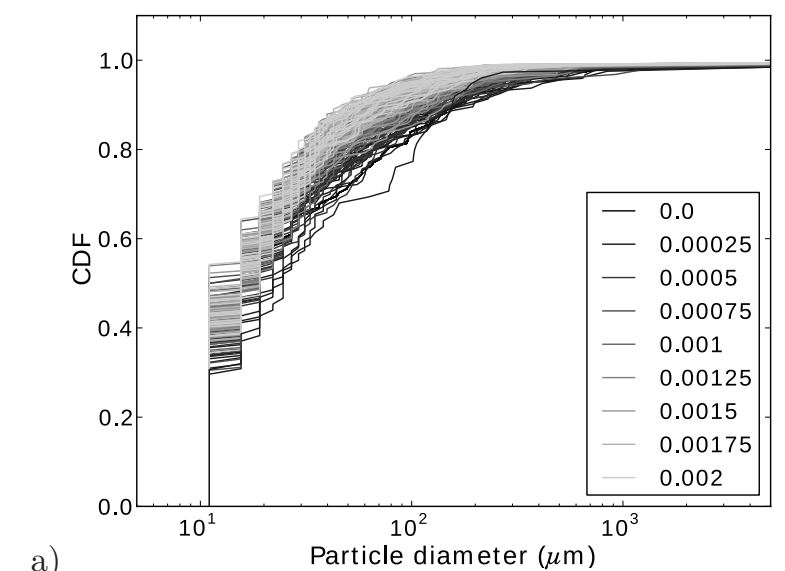

a)

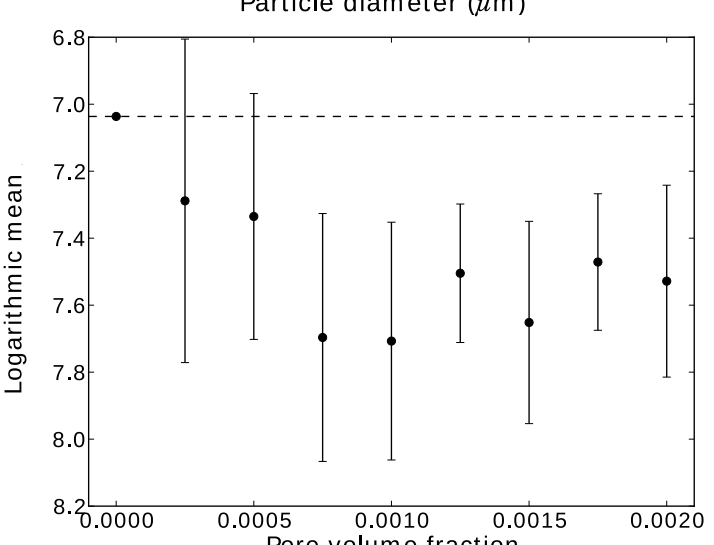

Figure 9: Spall-size distributions as a function of water-pocket volume fraction: a) Spall size distributions for simulations with $20 \mu \mathrm{m}$ radii micropores between $0.0 \%$ (black lines) and $0.2 \%$ (light gray) porosity. b) Average logarithmic means of the spall-size distributions from the microporosity simulations. 


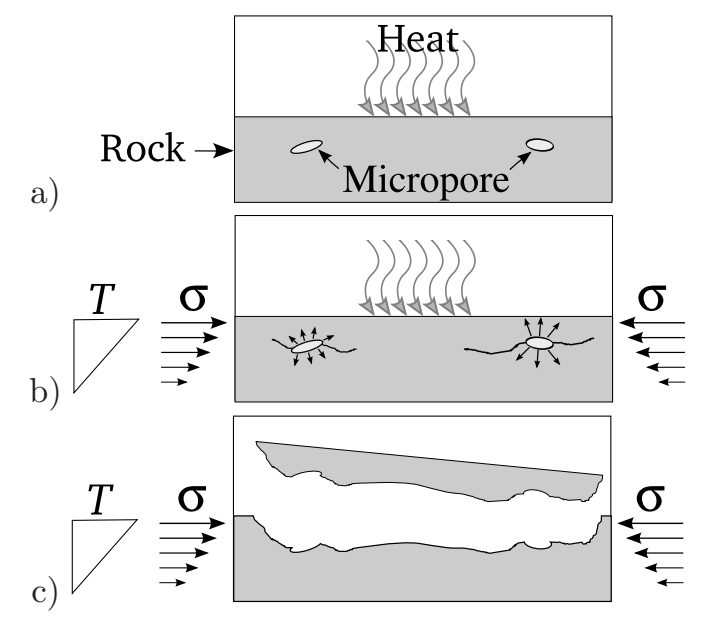

Figure 10: Pore-fluid enhanced spall-production model: a) the micropores serve as sites for fracture initiation caused by the rapid heating of the rock surface; b) the expansion of fluid within the pores aids in fracture propagation; c) fluid expansion and buckling causes the spall to be removed from the surface.

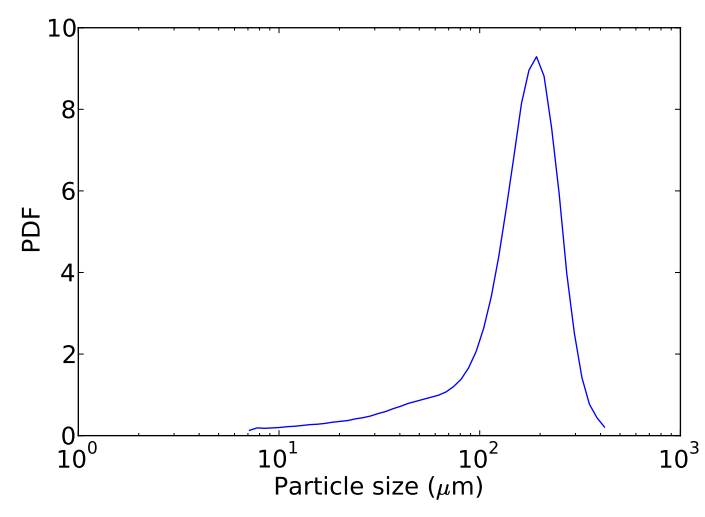

Figure 11: Spall size distribution collected from laboratory test of thermal spallation drilling into granite by Potter Drilling. 
a)

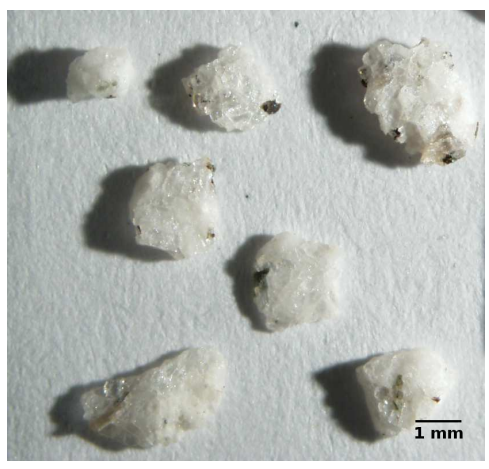

b)
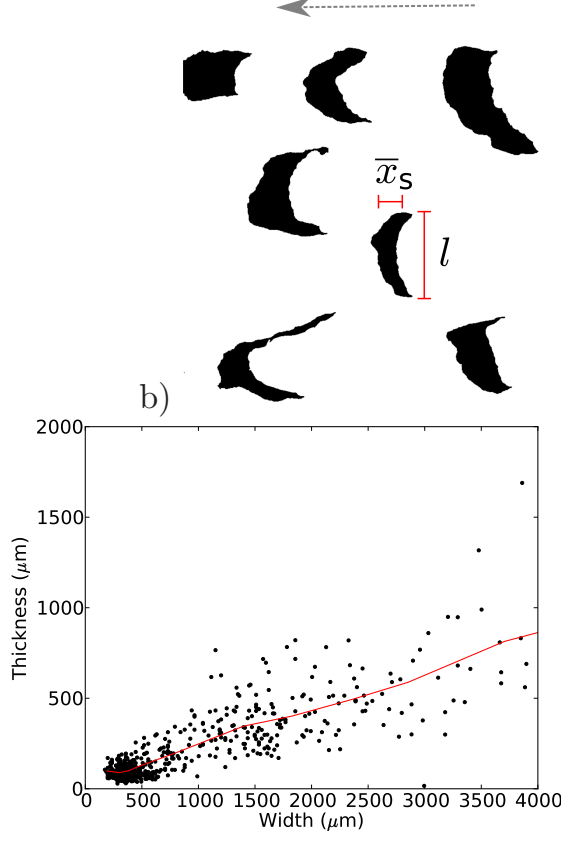

Lighting direction

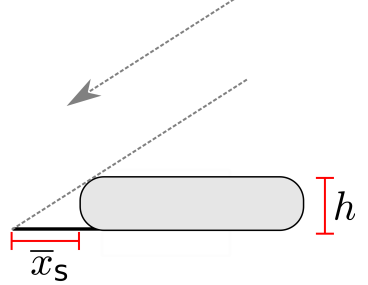

)

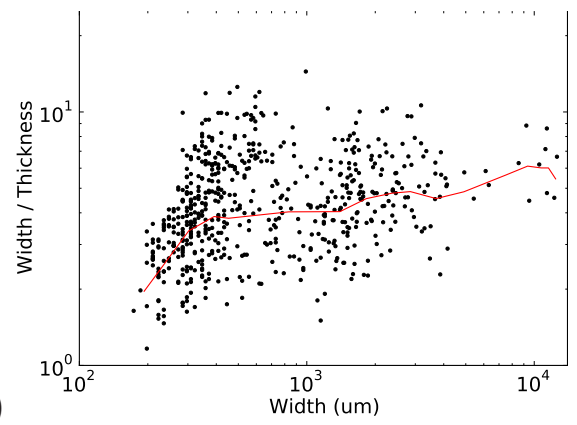

Figure 12: a) Spall particles are imaged under angled light and b) the extracted shadows are used to measure the length, $l$, and the average shadow extent $\bar{x}_{s}$ (from which the particle thickness $h$ is also determined). c) Measured average spall thicknesses plotted as a function of spall size. d) Ratio of spall size to average thickness as a function of spall size. Rolling average represented by red lines in c) and d). 
number of spall particles, we have not attempted to determine the principle axis of the individual particles, instead using the shadow extent to determine the cross-sectional width. For elongated particles this results in a smaller aspect ratio than would be determined had the maximum particle axis been used instead. However, this effect is fairly minor as most of the spalls examined were relatively circular in shape. An alternative explanation for the difference in observed aspect ratios may be that previous measurements have concentrated on larger particles, which tend to have a higher aspect ratio. It is also true that only a handful of studies have been conducted on this topic, and differences in aspect ratio may merely reflect differences in the rock properties and circumstances under which the spalls were collected.

The aspect ratio of the spalls is clearly a function of the spall size. As already noted, larger spalls tend to have larger aspect ratios, and there is a gradual decline from an average aspect ratio of around 6:1 for the very large spalls, to an average aspect ration of approximately 4:1 for particles around $1 \mathrm{~mm}$ in length. At around 400 microns however, the ratio decreases significantly, such that at 200 microns the aspect ratios are between 2:1 and $1: 1$, i.e. particles that are almost equant in shape. Similar trends were also observed in the spall particle aspect ratios from the numerical simulations (Figure 13). This sudden shift in the aspect ratio appears to be related to the average grain size of the granite. The exact cause is still somewhat inconclusive, however a likely explanation appears that while larger spalls can exploit existing planes of weakness, extremely small disk shaped particles are inhibited as new fracture planes must be initiated within previously undamaged rock.

To investigate what impact (if any) variable aspect ratio could have on predicted rates of thermal spallation, we have implemented the observed aspect-ratio changes in a simple Weibull-type failure model. Weibull failure theory postulates the existence of a distribution of size dependent failure strengths $\sigma_{f}$ represented by the following probability density distribution:

$$
G(\sigma)=1-\exp \left[\int_{0}^{V}\left(\frac{\sigma_{f}}{\sigma_{o}}\right)^{m} \mathrm{~d} V\right]
$$

where $\sigma_{o}$ is a material dependent parameter describing the material strength in a reference sample of unit volume. As originally proposed by Dey and Kranz $[17,18]$ and later adopted by Rauenzahn and Tester [19], it is assumed that spallation occurs for a point on the rock surface under "median conditions", i.e. when $G(\sigma)=0.5$. The differential volume in equation (14) describes the region in the rock that would remove the surface point if spallation was to occur. If it is assumed that the spall particles are thin circular 


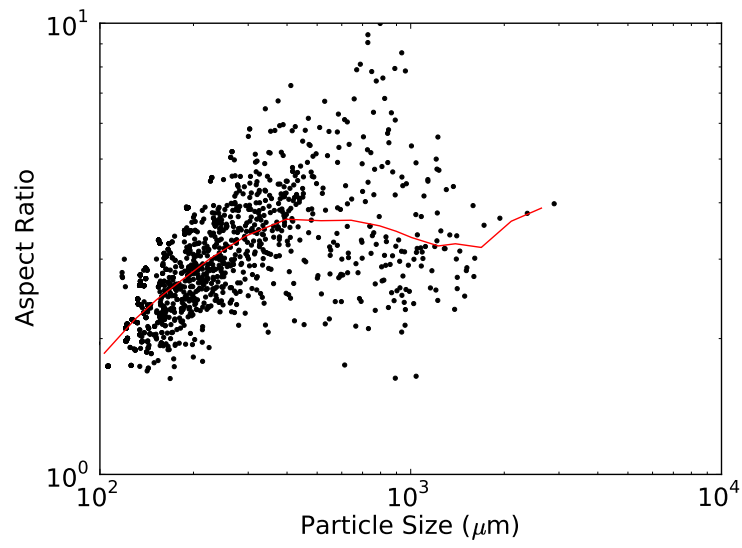

Figure 13: Simulated spall aspect ratios as a function of particle size. The red line represents a rolling average of the aspect ratios.

disks with an aspect ratio $C_{L}$, then the integrated volume is a cone with a cross-sectional area $\pi\left(C_{L} / 2\right)^{2}$. In addition, a quasi-static temperature profile based on a "subliming" rock model is adopted:

$$
T(x)=\left(T_{s}-T_{r}\right) \exp (-v x / \alpha)
$$

where $T$ is the temperature as a function of the position in the rock $x ; T_{s}$ and $T_{r}$ are the surface and far-field rock temperatures; $v$ is the velocity of the spalling rock/fluid interface; and $\alpha$ is the thermal diffusivity of the rock. with these assumptions, equation (14) can be rewritten

$$
\frac{\pi}{4}\left(\frac{\sigma_{s}}{\sigma_{o}}\right)^{m} \int_{0}^{V} C_{L}^{2} x^{2} \exp (-\omega x) \mathrm{d} V=\log (0.5)
$$

where $\omega=v m / \alpha$, and $\sigma_{s}$ is the stress at the surface. Implicit in this equation is the assumption that the maximum principle stresses are proportional to the increase in temperature:

$$
\sigma=\frac{\beta E \Delta T}{1-\nu},
$$

where $\beta$ is the thermal expansion of the rock, $E$ is the Young's modulus, and $\nu$ is the Poisson's ratio. In Dey and Kranz [17, 18] and Rauenzahn and Tester $[7,19]$, the spall aspect ratio is assumed constant, and hence the integral in equation (16) may be evaluated directly. In contrast, here, $C_{L}$ 
is assumed to be a function of the spall thickness $x$ to test the effect of the variable aspect ratio observed in the spall samples.

These equations yield the following expression for the heat flux through the surface of the rock, as a function of the rate of penetration, $v$.

$$
Q=\rho C_{p} v \frac{(1-\nu) \sigma_{o}}{\beta E}\left(\frac{4 \log (0.5)}{\pi}\right)^{1 / m}\left[\int_{0}^{\infty} C_{L}^{2} x^{2} \exp (-\omega x) \mathrm{d} x\right]^{-1 / m}
$$

From which the surface temperature may also be found, via:

$$
T_{s}=T_{r}+\frac{Q}{\rho C_{p} v} .
$$

Plots of the rate of penetration as a function of the heat flux and surface temperature increase are given in Figure 14. For one set of plots a constant aspect ratio $C_{L}=5$ is employed, while the second assumes a bimodal distribution of aspect ratios described by:

$$
C_{L}(x)= \begin{cases}1 & x<=100 \mu \mathrm{m} \\ 5 & x>100 \mu \mathrm{m}\end{cases}
$$

For the other parameters, we adopt similar values to those employed in Rauenzahn and Tester [7,19]: $\nu=0.25, E=45 G P a, \alpha=1 e-6 \mathrm{~m}^{2} / \mathrm{s}$, $\beta=1 e-5 \mathrm{~K}^{-1}, \sigma_{o}=70 \mathrm{MPa}$, with a slightly larger $m(m=21)$, to obtain a more appropriate temperature/spallation relationship.

The effect of the variable aspect ratio is to increase the heat flux needed to achieve a given penetration rate by approximately $15 \%$. More significant however is the effect on the predicted surface temperature, which is changed significantly by accounting for the spall aspect ratio distribution. This is particularly true at higher temperatures, as the scaled thermal penetration distance $\omega=m \alpha / v$, approaches the spall thickness associated with the aspect ratio transition.

\section{Conclusions and Recommendations for Future Models of Thermal Spallation in Rock}

Existing large-scale (i.e. borehole or continuum scale) models of thermal spallation are in need of further development. Simple models of spallation based on idealized geometries and buckling modes are insufficient to capture the heterogenity of natural systems. While, Weibull models provide a means of integrating heterogeneity into continuum-scale simulations, more work is 


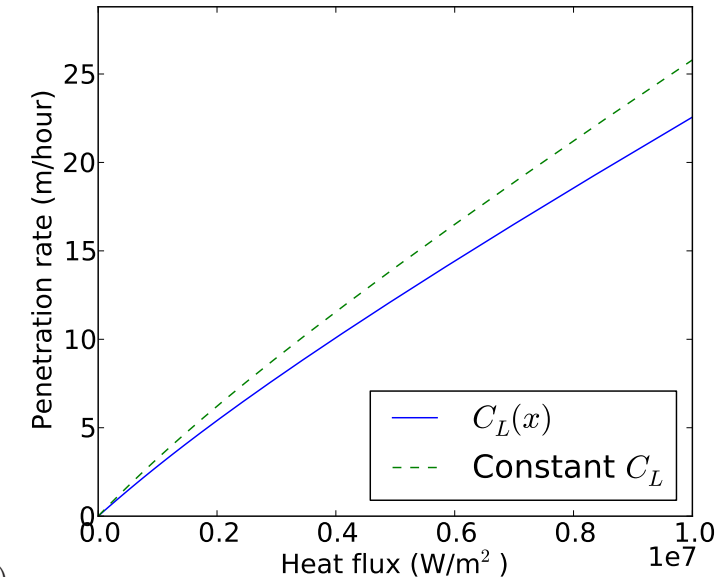

a)

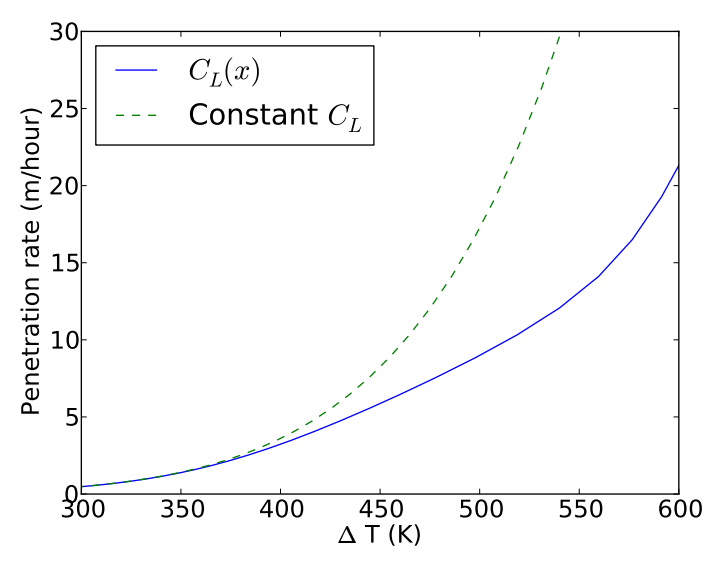

Figure 14: Plots of particle aspect ratio on the rate of penetration comparing results using a constant spall aspect ratio (dashed green line) versus a length dependent aspect ratio (solid blue line) given by equation 20 . 
required to a) validate or improve the assumptions that enter into such models, and b) relate empirical parameters to physical quantities. This latter point is vital in order to understand how such parameters might change under drilling conditions outside of the original experimental scope used to derive the model.

The results of our grain-scale simulations highlight the importance of microstructural effects in determining the mechanical response of granite under thermal spallation conditions. Such high resolution models, while not practical for bore-hole scale simulations, are vital in understanding the small-scale processes that drive larger scale phenomena. For example, our experiments and numerical simulations show that spall aspect ratio varies as a function of spall size. This has been overlooked in previous Weibull failure models, which for convenience and in the absence of evidence to the contrary have assumed a constant spall-size distribution. Nevertheless, as illustrated by the simple Weibull-type analysis presented in this report, variable spall sizes can influence the predicted rate of penetration significantly. Similarly, the results of the simulations conducted in this study have highlighted the role of microporosity in granite spallation. To date the effect of vapor pressure on granite spallation has been largely ignored. But from these simulations, it appears influential in determining spall initiation, as the rapid expansion of fluid within micropores serves to concentrate stresses at existing sites of weakness. Incorporating the effects of pore fluid content on the spall response is also clearly important when considering drilling in other rocks (most notably sandstones) as well as fractured media.

In this regard, the growing literature on thermal spallation in high performance cements may help to inform development of new continuum-scale spallation models. The two fields have focused on different but overlapping spalling regimes, with the rock community more focused on thermally induced buckling modes of failure, while in the cement literature there has been a natural interest in vapor pressure driven spallation. Continuumscale models integrating these two modeling frameworks will be of particular importance for predicting thermal spallation drilling performance across different rock types.

\section{Acknowledgments}

The authors gratefully acknowledge the Geothermal Technologies Program of the US Department of Energy for support of this work under the Enhanced Geothermal Systems Program. 
This work performed under the auspices of the U.S. Department of Energy by Lawrence Livermore National Laboratory under Contract DE-AC5207NA27344. This document was prepared as an account of work sponsored by an agency of the United States government. Neither the United States government nor Lawrence Livermore National Security, LLC, nor any of their employees makes any warranty, expressed or implied, or assumes any legal liability or responsibility for the accuracy, completeness, or usefulness of any information, apparatus, product, or process disclosed, or represents that its use would not infringe privately owned rights. Reference herein to any specific commercial product, process, or service by trade name, trademark, manufacturer, or otherwise does not necessarily constitute or imply its endorsement, recommendation, or favoring by the United States government or Lawrence Livermore National Security, LLC. The views and opinions of authors expressed herein do not necessarily state or reflect those of the United States government or Lawrence Livermore National Security, LLC, and shall not be used for advertising or product endorsement purposes.

\section{A Voronoi Cell Generation}

To generate Vornoi assemblies with predetermined particle size distributions, we first generate a Voronoi tesselation with the desired number of particles, then assign target volumes to each, and then perturb the system towards the desired solution by seeking a set of small voronoi center displacements $\delta x_{i}^{\beta}$ to satisfy the equation

$$
A_{\alpha, \beta_{i}} \delta x_{i}^{\beta}=\frac{\partial V^{\alpha}}{\partial x_{i}^{\beta}} \delta x_{i}^{\beta}=V_{\text {target }}^{\alpha}-V^{\alpha}
$$

The following subsections describe the construction of the $\frac{\partial V^{\alpha}}{\partial x_{i}^{\beta}}$ matrix in two and three dimensions. 


\section{A.1 Two Dimensions}

The volume of a voronoi cell (in 2D) can be expressed as

$$
\begin{aligned}
V & =\sum_{n} \frac{1}{2} e_{i j 3}\left(x_{i}^{n}-x_{i}^{0}\right)\left(l_{j}^{n+1, n}-l_{j}^{n, n-1}\right), \\
& =\sum_{n} \frac{1}{2} e_{i j 3} \Delta x_{i}^{n}\left(l_{j}^{n+1, n}-l_{j}^{n, n-1}\right), \\
& =\sum_{n} \frac{1}{2} e_{i j 3}\left(\Delta x_{i}^{n-1}-\Delta x_{i}^{n}\right) l_{j}^{n, n-1}
\end{aligned}
$$

where the sum is over the $n$ neighbors of the center point $x_{i}^{0}$, and $l_{j}^{n, n-1}$ is the vector from $x_{i}^{0}$ to the circumcenter of $x_{i}^{0}, x_{i}^{n}$ and $x_{i}^{n-1}$.

The location of the circumcenter relative to $x_{i}^{0}$ can be written in terms of the relative displacements $\Delta x_{i}^{n}=x_{i}^{n}-x_{i}^{0}$ and $\Delta x_{i}^{n-1}=x_{i}^{n-1}-x_{i}^{0}$,

$$
l_{i}^{n, n-1}=e_{i j 3}\left(\Delta x_{j}^{n} \Delta x_{k}^{n-1} \Delta x_{k}^{n-1}-\Delta x_{j}^{n-1} \Delta x_{k}^{n} \Delta x_{k}^{n}\right) /\left(2 e_{g h 3} \Delta x_{g}^{n-1} \Delta x_{h}^{n}\right) .
$$

The term $e_{i j 3} \Delta x_{i}^{n} l_{j}^{n, n-1}$ can be expressed as

$$
\begin{aligned}
e_{i j 3} \Delta x_{i}^{n} l_{j}^{n, n-1} & =-\Delta x_{j}^{n}\left(\Delta x_{j}^{n} \Delta x_{k}^{n-1} \Delta x_{k}^{n-1}-\Delta x_{j}^{n-1} \Delta x_{k}^{n} \Delta x_{k}^{n}\right) /\left(2 e_{g h 3} \Delta x_{g}^{n-1} \Delta x_{h}^{n}\right) \\
& =\frac{\Delta x_{j}^{n} \Delta x_{j}^{n} \Delta x_{k}^{n-1}\left(x_{k}^{n}-x_{k}^{n-1}\right)}{2 e_{g h 3} \Delta x_{g}^{n-1} \Delta x_{h}^{n}}
\end{aligned}
$$

Defining

$$
\begin{aligned}
f^{n, n-1} & =e_{i j 3}\left(\Delta x_{i}^{n-1}-\Delta x_{i}^{n}\right) l_{j}^{n, n-1} \\
& =\frac{\Delta x_{j}^{n} \Delta x_{j}^{n} \Delta x_{k}^{n-1}\left(x_{k}^{n-1}-x_{k}^{n}\right)+\Delta x_{j}^{n-1} \Delta x_{j}^{n-1} \Delta x_{k}^{n}\left(x_{k}^{n}-x_{k}^{n-1}\right)}{2 e_{g h 3} \Delta x_{g}^{n-1} \Delta x_{h}^{n}} \\
& =\frac{\left(\Delta x_{j}^{n} \Delta x_{j}^{n} \Delta x_{k}^{n-1}-\Delta x_{j}^{n-1} \Delta x_{j}^{n-1} \Delta x_{k}^{n}\right)\left(x_{k}^{n-1}-x_{k}^{n}\right)}{2 e_{g h 3} \Delta x_{g}^{n-1} \Delta x_{h}^{n}}
\end{aligned}
$$

then

$$
\begin{aligned}
\frac{\partial f^{n, n-1}}{\partial x_{i}^{o}}= & \frac{-2\left(\Delta x_{i}^{n} \Delta x_{k}^{n-1}-\Delta x_{i}^{n-1} \Delta x_{k}^{n}\right)\left(x_{k}^{n-1}-x_{k}^{n}\right)-\left(x_{i}^{n-1}-x_{i}^{n}\right)\left(\Delta x_{j}^{n} \Delta x_{j}^{n}-\Delta x_{j}^{n-1} \Delta x_{j}^{n-1}\right)}{2 e_{g h 3} \Delta x_{g}^{n-1} \Delta x_{h}^{n}} \\
& +\frac{1}{2} e_{i q 3}\left(x_{q}^{n}-x_{q}^{n-1}\right) \frac{\left(\Delta x_{j}^{n} \Delta x_{j}^{n} \Delta x_{k}^{n-1}-\Delta x_{j}^{n-1} \Delta x_{j}^{n-1} \Delta x_{k}^{n}\right)\left(x_{k}^{n-1}-x_{k}^{n}\right)}{\left(e_{g h 3} \Delta x_{g}^{n-1} \Delta x_{h}^{n}\right)^{2}}
\end{aligned}
$$




$$
\begin{aligned}
\frac{\partial f^{n, n-1}}{\partial x_{i}^{n}}= & \frac{2 \Delta x_{i}^{n} \Delta x_{k}^{n-1}\left(x_{k}^{n-1}-x_{k}^{n}\right)-\left(x_{i}^{n-1}-x_{i}^{n}\right) \Delta x_{j}^{n-1} \Delta x_{j}^{n-1}}{2 e_{g h 3} \Delta x_{g}^{n-1} \Delta x_{h}^{n}} \\
& +\frac{\Delta x_{j}^{n-1} \Delta x_{j}^{n-1} \Delta x_{i}^{n}-\Delta x_{j}^{n} \Delta x_{j}^{n} \Delta x_{i}^{n-1}}{2 e_{g h 3} \Delta x_{g}^{n-1} \Delta x_{h}^{n}} \\
& +\frac{1}{2} e_{i q 3} \Delta x_{q}^{n-1} \frac{\left(\Delta x_{j}^{n} \Delta x_{j}^{n} \Delta x_{k}^{n-1}-\Delta x_{j}^{n-1} \Delta x_{j}^{n-1} \Delta x_{k}^{n}\right)\left(x_{k}^{n-1}-x_{n}^{n}\right)}{\left(e_{g h 3} \Delta x_{g}^{n-1} \Delta x_{h}^{n}\right)^{2}} \\
\frac{\partial f^{n, n-1}}{\partial x_{i}^{n-1}=} & \frac{-2 \Delta x_{i}^{n-1} \Delta x_{k}^{n}\left(x_{k}^{n-1}-x_{k}^{n}\right)+\left(x_{i}^{n-1}-x_{i}^{n}\right) \Delta x_{j}^{n} \Delta x_{j}^{n}}{2 e_{g h 3} \Delta x_{g}^{n-1} \Delta x_{h}^{n}} \\
& +\frac{\Delta x_{j}^{n} \Delta x_{j}^{n} \Delta x_{i}^{n-1}-\Delta x_{j}^{n-1} \Delta x_{j}^{n-1} \Delta x_{i}^{n}}{2 e_{g h 3} \Delta x_{g}^{n-1} \Delta x_{h}^{n}} \\
& -\frac{1}{2} e_{i q 3} \Delta x_{q}^{n} \frac{\left(\Delta x_{j}^{n} \Delta x_{j}^{n} \Delta x_{k}^{n-1}-\Delta x_{j}^{n-1} \Delta x_{j}^{n-1} \Delta x_{k}^{n}\right)\left(x_{k}^{n-1}-x_{k}^{n}\right)}{\left(e_{g h 3} \Delta x_{g}^{n-1} \Delta x_{h}^{n}\right)^{2}}
\end{aligned}
$$

and $A_{\alpha, \beta_{i}}$ is given as

$$
A_{\alpha, \beta_{i}}=\frac{1}{4} \frac{\partial V^{\alpha}}{\partial x_{i}^{\beta}}=\frac{1}{4}\left(\frac{\partial f^{n, n-1}}{\partial x_{i}^{n}}+\frac{\partial f^{n+1, n}}{\partial x_{i}^{n}}\right)
$$

for $\alpha \neq \beta$ and where $x^{o}=x^{\alpha}$ and $x^{n}=x^{\beta}$ and

$$
A_{\alpha, \alpha_{i}}=\frac{\partial V^{\alpha}}{\partial x_{i}^{\alpha}}=\frac{1}{4} \sum_{n} \frac{\partial f^{n, n-1}}{\partial x_{i}^{o}}
$$

\section{A.2 Three dimensions}

The volume of a three dimensional voronoi cell is

$$
V=\sum_{t} V^{t}=\frac{1}{6} \sum_{t} e_{i j k} l_{i}^{t_{1}} l_{j}^{t_{2}} l_{k}^{t_{3}}
$$

where $V^{t}$ are the tetrahedron volumes and $l_{i}^{t}$ are the coordinates of the verticies of the vornoi cell associated with each tetrahedron relative to the cell node.

$$
\frac{\partial V^{t}}{\partial x_{i}^{\alpha}}=\frac{1}{6} \sum_{t} e_{p q r}\left(\frac{\partial l_{p}^{t_{1}}}{\partial x_{i}^{\alpha}} l_{q}^{t_{2}} l_{r}^{t_{3}}+l_{p}^{t_{1}} \frac{\partial l_{q}^{t_{2}}}{\partial x_{i}^{\alpha}} l_{r}^{t_{3}}+l_{p}^{t_{1}} l_{q}^{t_{2}} \frac{\partial l_{r}^{t_{3}}}{\partial x_{i}^{\alpha}}\right)
$$


The circumcenter of a tetrahedron is

$$
l_{i}^{s, t, u}=\frac{\Delta x_{h}^{s} \Delta x_{h}^{s} e_{i j k} \Delta x_{j}^{t} \Delta x_{k}^{u}+\Delta x_{h}^{t} \Delta x_{h}^{t} e_{i j k} \Delta x_{j}^{u} \Delta x_{k}^{s}+\Delta x_{h}^{u} \Delta x_{h}^{u} e_{i j k} \Delta x_{j}^{s} \Delta x_{k}^{t}}{2 e_{p q r} \Delta x_{p}^{s} \Delta x_{q}^{t} \Delta x_{r}^{u}}
$$

where $\Delta x_{p}^{s}, \Delta x_{q}^{t}$ and $\Delta x_{r}^{u}$ are arranged such that $e_{p q r} \Delta x_{p}^{s} \Delta x_{q}^{t} \Delta x_{r}^{u}>0$.

$$
\begin{aligned}
\frac{\partial l_{i}^{s, t, u}}{\partial x_{j}^{s}}= & \frac{1}{12 V}\left[2 \Delta x_{j}^{s} e_{i} g h \Delta x_{g}^{t} \Delta x_{h}^{u}+e_{i j g}\left(\Delta x_{k}^{u} \Delta x_{k}^{u} \Delta x_{g}^{t}-\Delta x_{k}^{t} \Delta x_{k}^{t} \Delta x_{g}^{u}\right)\right] \\
& -\frac{2 e_{i q r} \Delta x_{q}^{t} \Delta x_{r}^{u}}{(12 V)^{2}} e_{i g h}\left(\Delta x_{k}^{s} \Delta x_{k}^{s} \Delta x_{g}^{t} \Delta x_{h}^{u}\right. \\
& \left.+\Delta x_{k}^{t} \Delta x_{k}^{t} \Delta x_{g}^{u} \Delta x_{h}^{s}+\Delta x_{k}^{u} \Delta x_{k}^{u} \Delta x_{g}^{s} \Delta x_{h}^{t}\right)
\end{aligned}
$$

other derivatives can be obtained from cyclic permulations of $s, t, u$, and

$$
\frac{\partial l_{i}^{s, t, u}}{\partial x_{j}^{o}}=-\frac{\partial l_{i}^{s, t, u}}{\partial x_{j}^{s}}-\frac{\partial l_{i}^{s, t, u}}{\partial x_{j}^{t}}-\frac{\partial l_{i}^{s, t, u}}{\partial x_{j}^{u}}
$$

\section{References}

[1] F. W. Preston, The spalling of bricks, Journal of the American Ceramic Society 9 (10) (1926) 654-658. http://dx.doi.org/10.1111/j.1151-2916.1926.tb17115.x.

[2] F. W. Preston, H. E. White, Observations on spalling, Journal of the American Ceramic Society 17 (1-12) (1934) 137-144. http://dx.doi.org/10.1111/j.1151-2916.1934.tb19296.x.

[3] J. Browning, W. Horton, H. Hartman, Recent advances in flame jet working of minerals, in: Annual Symposium on Rock Mechanics, Pennsylvania State University, 1965.

[4] R. Rinaldi, A technical and economic evaluation of thermal spallation drilling technology (1984) 253.

[5] R. M. Potter, J. M. Potter, T. W. Wideman, Laboratory study and field demonstration of hydrothermal spallation drilling, GRC Transactions 34 (2010) 249-252. 
[6] J. J. Calaman, H. C. Rolseth, Technical advances expand use of jetpiercing process in taconite industry, in: International Symposium on Mining Research, U.S. Bureau of Mines, 1961.

[7] R. Rauenzahn, J. Tester, Rock failure mechanisms of flame-jet thermal spallation drilling-theory and experimental testing, International Journal of Rock Mechanics and Mining Sciences \& Geomechanics Abstracts 26 (5) (1989) 381 - 399. http://dx.doi.org/DOI: $10.1016 / 0148-9062$ (89) 90935-2.

[8] R. W. Stacey, S. Sanyal, J. Potter, T. Wideman, Effectiveness of selective borehole enlargement to improve flow performance of geothermal wells, GRC Transactions 35 (2011) 239-245.

[9] T. W. Wideman, N. Sazdanoff, J. Unzelman-Langsdorf, J. M. Potter, Hydrothermal spallation for the treatment of hydrothermal and egs wells: A cost-effective method for substantially increasing reservoir production and flow rates, GRC Transactions 35 (2011) 283-285.

[10] A. Smith, P. Pells, Impact of fire on tunnels in hawkesbury sandstone, Tunnelling and Underground Space Technology 23 (1) (2008) $65-74$. http://dx.doi.org/10.1016/j.tust.2006.11.003.

[11] P. Zhang, E. Nordlund, G. Mainalia, C. Saiang, R. Jansson, B. AdlZarrabi, Experimental study of thermal spalling of rock blocks exposed to fire, Bergmekanik I Norden (2010) 9-12.

[12] W. Gray, Surface spalling by thermal stresses in rocks, in: 3rd Canadian Symposium on Rock Mechanics, University of Toronto, 1965.

[13] K. Larsson, Fires in tunnels and their effect on rock: a review.

[14] L. Germanovich, Thermal spalling of rock, Advances in fracture research 6 (1997) 2771-2782.

[15] K. Thirumalai, Process of thermal spalling behavior in rocks an exploratory study, in: The 11th US Symposium on Rock Mechanics (USRMS), 1969.

[16] W. Weibull, A statistical distribution function of wide applicability, Journal of applied mechanics 18 (1951) 292-297.

[17] T. N. Dey, R. L. Kranz, Methods for increasing drilling performance of the thermal spallation drilling system, GRC Transactions 9 (1985) 103-106. 
[18] T. N. Dey, R. L. Kranz, Flake mechanics, borehole breakouts and thermal spallation, in: I. Farmer, J. Daemen, C. Desai, C.E.Glass, S. Neuman (Eds.), Proceedings of the 28th US Symposium on Rock Mechanics, 1987.

[19] R. M. Rauenzahn, J. W. Tester, Numerical simulation and field testing of flame-jet thermal spallation drilling-1. model development, International Journal of Heat and Mass Transfer 34 (3) (1991) $795-808$. http://dx.doi.org/DOI : 10.1016/0017-9310(91)90126-Y.

[20] M. A. Wilkinson, J. W. Tester, Computational modeling of the gasphase transport phenomena during flame-jet thermal spallation drilling, International Journal of Heat and Mass Transfer 36 (14) (1993) 3459 3475. http://dx.doi.org/DOI: 10.1016/0017-9310(93)90164-2.

[21] T. H. Antoun, I. N. Lomov, L. A. Glenn, Development and application of a strength and damage model for rock under dynamic loading, in: D. Elsworth, J. Tinucci, K. Heasley (Eds.), Proceedings of the 38th U.S. Rock Mechanics Symposium, Rock Mechanics in the National Interest, A. A. Balkema Publishers, 2001, p. 369374.

[22] I. Lomov, M. Rubin, Numerical simulation of damage using an elasticviscoplastic model with directional tensile failure, Journal De Physique IV 110 (2003) 281286.

[23] E. S. J. Hertel, R. L. Bell, An improved material interface reconstruction algorithm for Eulerian codes, Sandia Nat Lab, 1992.

[24] M. B. Rubin, I. Lomov, A thermodynamically consistent large deformation elastic-viscoplastic model with directional tensile failure, International Journal of Solids and Structures 40 (17) (2003) 4299 - 4318. http://dx.doi.org/DOI: 10.1016/S0020-7683(03)00242-7.

[25] J. Soles, L. Geller, Experimental Studies Relating Mineralogical and Petrographic Features to the Thermal Piercing of Rocks, Technical bulletin (Canada. Mines Branch), Department of Mines and Technical Surveys, Mines Branch, 1964.

[26] C. Tong, Psuade user's manual, Lawrence Livermore National Laboratory (LLNL), Livermore, CA 109.

[27] G. H. Miller, E. G. Puckett, A high-order godunov method for multiple condensed phases, Journal of Computational Physics 128 (1) (1996) 134-164. 
[28] J. Newman, K. Thomas-Alyea, Electrochemical systems, Wiley Hoboken, NJ, 2004.

[29] E. B. Herbold, O. Y. Vorobiev, S. D. C. Walsh, Composing heterogeneous microstructures (2012) In preparation.

[30] J. D. Bass, Elasticity of minerals, glasses, and melts, in: T. J. Ahrens (Ed.), Mineral Physics and CrystallographyHandbook of Physical Constants, AGU Reference Shelf, Vol 2, American Geophysical Union, 1995, pp. $45-63$.

[31] G. Mavko, T. Mukerji, J. Dvorkin, The Rock Physics Handbook. Tools for Seismic Analysis of Porous Media, Cambridge University Press, 2003.

[32] A. Findikakis, Heat capacity analysis report, Bechtel SAIC Company (2004) DOE Technical Report (ANL-NBS-GS-000013, REV 01).

[33] T. Holland, R. Powell, An internally consistent thermodynamic data set for phases of petrological interest, Journal of metamorphic Geology 16 (3) (1998) 309-343.

[34] C. Clauser, E. Huenges, Thermal conductivity of rocks and minerals, in: T. J. Ahrens (Ed.), Rock Physics and Phase Relations Handbook of Physical Constants, AGU Reference Shelf, Vol 3, American Geophysical Union, 1995, pp. 105-126.

[35] D. Lockner, A generalized law for brittle deformation of westerly granite, Journal of Geophysical Research 103 (B3) (1998) 5107-5123.

[36] S. D. C. Walsh, I. Lomov, J. J. Roberts, Geomechanical modeling for thermal spallation drilling, GRC Transactions 35 (2011) 277-282.

[37] S. D. C. Walsh, I. Lomov, J. J. Roberts, Grain-scale failure in thermal spallation drilling, in: PROCEEDINGS, Thirty-Seventh Workshop on Geothermal Reservoir Engineering, Stanford University, Stanford, California, 2012, pp. SGP-TR-194.

[38] D. Moore, D. Lockner, The role of microcracking in shear-fracture propagation in granite, Journal of Structural Geology 17 (1) (1995) 95-114.

[39] R. Rauenzahn, Analysis of rock mechanics and gas dynamics of flamejet thermal spallation drilling, Ph.D. thesis, Massachusetts Institute of Technology (1986). 
[40] P. Kalifa, F. Menneteau, D. Quenard, Spalling and pore pressure in hpc at high temperatures, Cement and concrete research 30 (12) (2000) 1915-1927.

[41] M. Kanema, M. de Morais, A. Noumowe, J. Gallias, R. Cabrillac, Experimental and numerical studies of thermo-hydrous transfers in concrete exposed to high temperature, Heat and Mass Transfer 44 (2) (2007) 149-164.

[42] J. Mindeguia, P. Pimienta, A. Noumowé, M. Kanema, Temperature, pore pressure and mass variation of concrete subjected to high temperature-experimental and numerical discussion on spalling risk, Cement and Concrete Research 40 (3) (2010) 477-487.

[43] G. van der Heijden, L. Pel, O. Adan, Fire spalling of concrete, as studied by nmr, Cement and Concrete Research 42 (2) (2012) 265 - 271. http://dx.doi.org/10.1016/j.cemconres.2011.09.014.

[44] M. Hettema, K.-H. Wolf, C. D. Pater, The influence of steam pressure on thermal spalling of sedimentary rock: Theory and experiments, International Journal of Rock Mechanics and Mining Sciences 35 (1) (1998) 3 - 15. http://dx.doi.org/10.1016/S0148-9062(97)00318-5.

[45] K. Hertz, Limits of spalling of fire-exposed concrete, Fire Safety Journal 38 (2) (2003) 103 - 116. http://dx.doi.org/10.1016/S0379-7112(02)00051-6.

[46] C. W. Montgomery, W. F. Brace, Micropores in plagioclase, Contributions to Mineralogy and Petrology 52 (1975) 17-28, 10.1007/BF00377999.

[47] F. Homand-Etienne, R. Houpert, Thermally induced microcracking in granites: characterization and analysis, International Journal of Rock Mechanics and Mining Sciences \& Geomechanics Abstracts 26 (2) (1989) 125 - 134. http://dx.doi.org/10.1016/0148-9062(89)90001-6.

[48] G. van der Heijden, R. van Bijnen, L. Pel, H. Huinink, Moisture transport in heated concrete, as studied by nmr, and its consequences for fire spalling, Cement and Concrete Research 37 (6) (2007) $894-901$. http://dx.doi.org/10.1016/j.cemconres.2007.03.004. 
[49] L. Geller, A new look at thermal rock fracturing, Trans. Inst. Min. Metall 79 (1970) A133-A170. 